\title{
Comparative efficacy of eptifibatide and abciximab in primary angioplasty study
}

This article was published in the following Dove Press journal:

Research Reports in Clinical Cardiology

7 February 201 I

Number of times this article has been viewed

Rohan Jayasinghe'

Matias Yudi'

Sanjay Jayasinghe ${ }^{2}$

'Cardiology Department, Gold Coast Hospital, Griffith University, Queensland, Australia; ${ }^{2}$ Centre for Immunisation Research, Sydney,

Australia
Correspondence: Rohan Jayasinghe Cardiology Department, Gold Coast Hospital, Griffith University, Level 9, 108 Nerang Street, Southport, Queensland, Australia 4215

Tel +6I 42I58I296

Fax +6I 755198839

Email roheart2000@yahoo.com
Background: Primary percutaneous intervention is the safest and most effective treatment modality for acute ST-segment elevation myocardial infarction (MI) in centers where catheterization facilities exist. Intravenous glycoprotein IIb/IIIa inhibitor therapy during the procedures has been proven to provide added benefits. For the two agents, abciximab and eptifibatide, commonly used in this context, there is only limited comparative data available for the clinicians. Hitherto, there is no data published from the Asia-Pacific region on this topic.

Method: A retrospective comprehensive analysis was carried out, comparing patients who were treated with abciximab $(n=125)$ and eptifibatide $(n=125)$ during primary angioplasty over a 3 -year period. The primary outcome measure was in-hospital mortality. The other outcome measures studied include MI, stroke, blood transfusion, contrast nephropathy, significant bleeding, and vascular complications. A comparative cost analysis was carried out to ascertain the average overall differential cost.

Results: In-hospital mortality, MI, stroke, blood transfusion, contrast nephropathy, significant bleeding, and vascular complication were observed at a higher rate in the patients who were treated with abciximab. However, these differences did not reach statistical significance. Due to the higher cost per unit and longer hospital stay, therapy with abciximab costs more than that with eptifibatide.

Conclusions: Both abciximab and eptifibatide are safe and effective adjunct therapeutic agents in the setting of primary angioplasty. However, there is a trend toward higher adverse event with the former agent that was not statistically significant. Therapy with abciximab costs more per patient.

Keywords: abciximab, eptifibatide, PCI, STEMI

\section{Introduction}

Primary percutaneous coronary intervention (PCI) is the preferred treatment for patients with ST-segment elevation myocardial infarction (STEMI). Increased understanding of the role of platelets in acute myocardial infarction (MI) has led to the successful use of glycoprotein (GP) IIb/IIIa inhibitors as adjunctive therapy in this setting. Evidence is particularly convincing for the use of abciximab, the oldest and more widely studied GP IIb/IIIa inhibitor, in STEMI patients. ${ }^{1,2}$ Eptifibatide is a small molecule GP IIb/IIIa inhibitor that shares some pharmacological properties with abciximab. There is an emerging body of evidence to support its use in primary PCI. ${ }^{3,4}$ However, this body of published evidence is confined only to sources in North America. ${ }^{5}$ This article contains the first published comparative evidence on this subject from the Asia-Pacific region. Only one small randomized clinical trial comparing the safety and efficacy of these 
two agents in the setting of primary PCI has been hitherto undertaken. ${ }^{6}$ Given the prevailing trends where sponsored trials are focusing on novel agents that inhibit other targets in the coagulation cascade, it is highly unlikely that any more head-to-head trials comparing these two agents would take place in the future.

The limited published evidence from the observational studies and the single randomized control study ${ }^{5-7}$ have shown no difference in efficacy between abciximab and eptifibatide in the setting of primary PCI. There has been a higher rate of gastrointestinal bleeding observed with abciximab in one of the studies published. ${ }^{7}$ We retrospectively analyzed 250 consecutive patients who underwent primary PCI at our center, who were given adjunctive GP IIb/IIIa inhibitors during primary PCI for short-term clinical outcomes of mortality, length of hospital stay, recurrent cardiovascular events, revascularization (including coronary artery bypass graft (CABG) surgery), and bleeding complications. A cost analysis was carried out to ascertain the comparative cost efficacy between the two agents per patient treated.

\section{Methodology}

The study population included consecutive patients who underwent primary PCI for STEMI with adjunct periprocedure therapy with either abciximab or eptifibatide at the Gold Coast Hospital (GCH), Queensland, Australia, between April 2005 and March 2008. Both agents were available in the hospital formulary for use for this indication throughout the study period. Patients treated with adjunct upstream tirofiban and those who underwent rescue PCI after failed thrombolysis were excluded from the study.

Data were extracted from the medical records of the patient cohort qualified for inclusion by the investigators. Baseline data include demographics, clinical presentation, body weight and height, cardiovascular risk factor profile, and the medication profile. The angiogram report, consequent postprocedural medical records, and documented clinical records were used to collate and accurately gather the relevant ancillary clinical information and consequent outcomes of our target population.

All catheterization procedures were performed using standard coronary intervention techniques. The use of either abciximab or eptifibatide was at the discretion of the interventional cardiologist. Both agents were licensed for use in primary PCI and readily available throughout the study period. There was no criteria-led position statement at our institution to guide the treating interventionist on their use, so the choice of agent was based on operator discretion. Abciximab was administered as an intravenous bolus of $0.25 \mathrm{mg} / \mathrm{kg}$ body weight, followed by an infusion at $0.125 \mathrm{mg} / \mathrm{kg} / \mathrm{min}$ for up to $12 \mathrm{~h}$. Eptifibatide was administered in two bolus infusions $10 \mathrm{~min}$ apart, at $180 \mu \mathrm{g} / \mathrm{kg}$, followed by an infusion at $2 \mu \mathrm{g} / \mathrm{kg} / \mathrm{min}$ for up to $18 \mathrm{~h}$. There were adjustments made to the dose of eptifibatide according to the individual patient's renal function. Angiographic success upon intervention was defined by residual stenosis of $<50 \%$ diameter of the index coronary segment and reestablishment of thrombolysis in myocardial infarction (TIMI) flow grade 3 coronary reflow.

The primary end point of this study was in-hospital mortality. The secondary end points were MI; stroke; length of hospital stay; revascularization, including $\mathrm{CABG}$ surgery; need for postprocedure blood transfusion; contrast nephropathy; significant bleeding; and vascular complications over a 3-month period. This time period was chosen as it corresponded with the routine 3-month post-PCI specialist outpatient consultation. Short-term in-hospital mortality included mortality both due to cardiac and noncardiac causes. Postprocedural blood transfusions were included irrespective of the number of units given. The collective term vascular complications encompassed the following: pseudoaneurysm; retroperitoneal hematoma; hematoma at access site requiring transfusion or prolonged hospital stay; and access site complication requiring repair.

SPSS software (version 15; SPSS, Chicago, IL) was used for data analysis. For categorical variables, observed frequencies and percentages are presented. Mean values and standard deviations are presented for continuous variables. The $\chi^{2}$ and Fisher's exact tests were used to compare the two treatment groups for categorical variables. Student's $t$-test was used for the comparison of continuous data. A logistic regression analysis was carried out to determine adjusted odds of periprocedural events (study outcomes) with the use of abciximab.

The National Ethics Application Form for this study was approved by the institutional human ethics review committee. The data were collected by medical research team of the cardiology department at the $\mathrm{GCH}$, and it was then collated by the principal investigator. An audit was performed on a randomly selected series of charts to ensure accuracy of the data collection.

\section{Results}

During the study period, 250 patients, who were treated with either abciximab $(n=125)$ or eptifibatide $(n=125)$ qualified for the analysis, underwent primary PCI for STEMI. 
Table I Baseline demographics and clinical characteristics of patients treated with abciximab or eptifibatide

\begin{tabular}{|c|c|c|c|c|c|}
\hline & Abciximab & & Eptifibatide & & $P$ value \\
\hline Number of patients & 125 & & 125 & & \\
\hline Male & 92 & $73.6 \%$ & 101 & $80.8 \%$ & \\
\hline Female & 33 & $26.4 \%$ & 24 & $19.2 \%$ & 0.23 \\
\hline Mean age (years) & 63.03 (SD II.04) & & 61.50 (SD I2.78) & & 0.31 \\
\hline Mean weight (kg) & 81.78 & & 81.89 & & 0.43 \\
\hline Mean height $(\mathrm{cm})$ & 171.53 (SD 8.66) & & 171.13 (SD I7.25) & & 0.22 \\
\hline Hypertension & 63 & $50.4 \%$ & 79 & $63.2 \%$ & 0.54 \\
\hline Diabetes mellitus & 20 & $16.0 \%$ & 21 & $16.8 \%$ & 0.9 \\
\hline Dyslipidemia & 53 & $42.4 \%$ & 30 & $24.0 \%$ & 0.24 \\
\hline Positive family history & 37 & $29.6 \%$ & 18 & $14.4 \%$ & 0.38 \\
\hline Prior myocardial infarction & 33 & $26.4 \%$ & 12 & $9.6 \%$ & 0.2 \\
\hline Heart failure & 7 & $5.6 \%$ & 2 & $1.6 \%$ & 0.34 \\
\hline Renal failure & 7 & $5.6 \%$ & I & $0.8 \%$ & 0.035 \\
\hline PVD & 19 & $15.2 \%$ & 2 & $1.6 \%$ & 0.006 \\
\hline Cardiac arrest & 2 & $1.6 \%$ & 2 & $1.6 \%$ & 0.68 \\
\hline Atrial fibrillation & 10 & $8.0 \%$ & 1 & $0.8 \%$ & 0.05 \\
\hline Previous PCl & 18 & $14.4 \%$ & 10 & $8.0 \%$ & 0.244 \\
\hline Previous CABG & 6 & $4.8 \%$ & 7 & $5.6 \%$ & 0.78 \\
\hline
\end{tabular}

Abbreviations: $\mathrm{PVD}$, peripheral vascular disease; $\mathrm{PCl}$, percutaneous coronary intervention; $\mathrm{CABG}$, coronary artery bypass graft.

There was no significant temporal discordance in the use of the agents, with abciximab being used $56 \%$ of the time in the first 18 months of the study and $44 \%$ of the time in the second 18 months. The baseline demographic and clinical characteristics are shown in Table 1. The majority of patients in both groups were male. Patients in the abciximab arm were more likely to have hypercholesterolemia (42.4\% vs $24 \%)$, peripheral vascular disease (PVD) (15.2\% vs $1.6 \%)$, a positive family history of premature coronary artery disease ( $29.6 \%$ vs $14.4 \%$ ), past history of MIs ( $26.4 \%$ vs $9.6 \%$ ), atrial fibrillation (AF) ( $8 \%$ vs $0.8 \%$ ), previous PCI ( $14.4 \%$ vs $8 \%$ ), and renal failure ( $5.6 \%$ vs $0.8 \%$ ). The baseline clinical characteristics of the two groups were statistically comparable in that only the preponderance of PVD and renal failure were statistically significant $(P<0.05)$. Patients in the eptifibatide arm were more likely to be smokers ( $36 \%$ vs $27.2 \%)$ and hypertensive (63.2\% vs $50.4 \%)$. Regarding preprocedural treatment (Table 2), the eptifibatide group had higher use of clopidogrel, lipid-lowering medications (statins), ACE inhibitors, calcium channel blockers, and beta-blockers. Abciximab group was more likely to have been treated with unfractionated heparin (UFH).

Table 3 shows the procedural and outcome parameters of the two groups. Patients in the abciximab group were more likely to experience cardiac arrest, cardiogenic shock, ventricular fibrillation, and ventricular tachycardia. They were also exposed to a larger amount of contrast (269 vs $234 \mathrm{~mL}$ ). The abciximab group required intraaortic balloon pump (IABP) assistance $(P=0.06)$ during and after the procedure at a higher frequency. In regard to angiographic success, the abciximab group had a significantly greater rate of angiographic success in relation to residual diameter stenosis $(P<0.001)$. There was, however, no difference in postprocedural TIMI grade 3 coronary flow between the groups.

The unadjusted outcome measures included are compared in Table 4. There were four in-hospital deaths in the abciximab arm with no deaths in the eptifibatide arm. The average length of stay was longer in the abciximab arm. Though these differences did not reach statistical significance, the clinical significance cannot be overlooked. Three patients suffered strokes in the abciximab arm and none in the eptifibatide arm. Of note were the higher rates of vascular complications, contrast nephropathy, stroke, MI, and revascularization in

Table 2 Preprocedural treatments for patients treated with abciximab and eptifibatide post-PCI for STEMI

\begin{tabular}{llllll}
\hline & Abciximab & & Eptifibatide & P-value \\
\hline LMWH & 9 & $7.2 \%$ & 22 & $17.6 \%$ & 0.58 \\
UFH & 115 & $92.0 \%$ & 89 & $71.2 \%$ & $<0.00 \mathrm{I}$ \\
Aspirin & 118 & $94.4 \%$ & 122 & $97.6 \%$ & 0.12 \\
Clopidogrel & $1 \mathrm{II}$ & $88.8 \%$ & 123 & $98.4 \%$ & 0.09 \\
Lipid therapy & 72 & $57.6 \%$ & $\mathrm{III}$ & $88.8 \%$ & $<0.00 \mathrm{I}$ \\
ACE inhibitor & 48 & $38.4 \%$ & 87 & $69.6 \%$ & $<0.00 \mathrm{I}$ \\
Beta-blocker & 60 & $48.0 \%$ & $\mathrm{I} 104$ & $83.2 \%$ & $<0.00 \mathrm{I}$ \\
Ca $^{2+}$ channel & 7 & $5.6 \%$ & 27 & $21.6 \%$ & 0.039 \\
blocker & & & & & \\
Diuretic & 16 & $12.8 \%$ & 14 & $11.2 \%$ & 0.85 \\
\hline
\end{tabular}

Abbreviations: LMWH, low molecular weight heparin; UFH, unfractionated heparin; $\mathrm{ACE}$, angiotensin-converting enzyme; $\mathrm{Ca}^{2+}$, calcium; $\mathrm{PCl}$, percutaneous coronary intervention; STEMI, ST-segment elevation myocardial infarction. 
Table 3 Characteristics of procedural findings in patients treated with either abciximab or eptifibatide

\begin{tabular}{|c|c|c|c|c|c|}
\hline & Abciximab & & Eptifibatide & & $P$-value \\
\hline Average length of stay (days) & 4.52 (SD 3.35) & & 3.37 (SD 4.I0) & & 0.09 \\
\hline Cardiac arrest & 8 & $6.4 \%$ & 2 & $1.6 \%$ & 0.06 \\
\hline Cardiogenic shock & 5 & $4.0 \%$ & I & $0.8 \%$ & 0.12 \\
\hline $\mathrm{VT} / \mathrm{VF}$ & 10 & $8.0 \%$ & 6 & $4.8 \%$ & 0.31 \\
\hline Mean total contrast (mL) & 268.99 & & 234.39 & & \\
\hline Single vessel CAD (>70\%) & 38 & $30.4 \%$ & 51 & $40.8 \%$ & 0.11 \\
\hline Two-vessel CAD & 51 & $40.8 \%$ & 37 & $29.6 \%$ & 0.05 \\
\hline Three-vessel CAD & 35 & $28.0 \%$ & 43 & $34.4 \%$ & 0.52 \\
\hline $\mathrm{PCl}$ one vessel & 100 & $80.0 \%$ & 102 & $81.6 \%$ & 0.87 \\
\hline $\mathrm{PCl}$ two vessels & 21 & $16.8 \%$ & 17 & $13.6 \%$ & 0.48 \\
\hline $\mathrm{PCl}$ three vessels & 0 & $0.0 \%$ & 3 & $2.4 \%$ & 0.25 \\
\hline One lesion & 85 & $68.0 \%$ & 80 & $64.0 \%$ & 0.58 \\
\hline Two lesions & 29 & $23.2 \%$ & 33 & $26.4 \%$ & 0.36 \\
\hline Three+ lesions & 8 & $6.4 \%$ & 13 & $10.4 \%$ & 0.53 \\
\hline LM stenosis $>70 \%$ & 12 & $9.6 \%$ & 6 & $4.8 \%$ & 0.22 \\
\hline Restenotic lesion & 10 & $8.0 \%$ & 4 & $3.2 \%$ & 0.16 \\
\hline IABP & 7 & $5.6 \%$ & 1 & $0.8 \%$ & 0.06 \\
\hline Calcification & 8 & $6.4 \%$ & 4 & $3.2 \%$ & 0.38 \\
\hline
\end{tabular}

Abbreviations: VT, ventricular arrhythmia; VF, ventricular fibrillation; CAD, coronary artery disease; PCI, percutaneous coronary intervention; IABP, intraaortic balloon pump; LM, left main.

the abciximab group though these did not reach statistical significance. Though the bleeding rates were equal between the two arms, the patients in the abciximab arm required more transfusions. Seven patients in the abciximab arm required CABG surgery during the follow-up period compared to one in the eptifibatide arm.

An effort was made to compare outcomes in the patients between groups; however, due to the small number of events, no meaningful statistical difference was found (Table 5). As there were no deaths recorded in the eptifibatide arm, odds ratio could not be calculated for the primary end point of in-hospital mortality. Consequently, a combined outcomes measure of major adverse cardiovascular events (MACEs) was calculated. The probability of the occurrence of observed outcomes with the use of abciximab and eptifibatide was assessed using a regression analysis. A binary logistic regression model was fitted with the composite outcome MACE as the dependent variable. The baseline characteristics that were significantly different between the two treatment groups were entered as covariates in the model to obtain an adjusted odds ratio. All predictor variables were entered as a block in a single step in the model. Due to the rarity of occurrence of individual outcomes in the study, only crude (unadjusted) odds ratios were calculated for them (Table 5). The calculated MACE was statistically significant in favor of eptifibatide (odds ratio [OR]: 3.94, 95\% confidence intervals [CI]: 1.39-11.2).

Statistical significance level was defined at $P<0.05$ for all analyses.

The analysis of data related to the echocardiographic left ventricular function assessment during the index presentation

Table 4 Unadjusted outcome of the cohort categorized by treatment

\begin{tabular}{llll}
\hline Outcome & Abciximab (\%) & Eptifibatide (\%) & P-value \\
\hline Postprocedural TIMI flow grade 3 success & $119(96)$ & $115(96.6)$ & 0.55 \\
Postprocedural stenosis of $<50 \%$ angiographic diameter & $114(91.9)$ & $87(70.7)$ & $<0.001$ \\
Coronary artery bypass surgery & $7(5.6)$ & $1(0.8)$ & 0.21 \\
GI bleeding & $3(2.4)$ & $2(1.6)$ & 0.5 \\
Vascular complications & $3(2.4)$ & $0(0)$ & 0.25 \\
Contrast nephropathy & $3(2.4)$ & $2(1.6)$ & 0.5 \\
Postprocedure transfusion & $4(3.3)$ & $0(0)$ & 0.12 \\
Stroke & $3(2.4)$ & $0(0)$ & 0.25 \\
Myocardial infarction & $4(3.3)$ & $2(1.6)$ & 0.68 \\
Death & $4(3.3)$ & $0(0)$ & 0.12 \\
Revascularization & $8(6.5)$ & $4(3.3)$ & 0.188 \\
MACE & $26(20.8)$ & $7(5.6)$ & 0.015 \\
\hline
\end{tabular}

Abbreviations: MACE, major adverse cardiovascular events; TIMI, thrombolysis in myocardial infarction; Gl, gastrointestinal. 
Table 5 The probability of in-hospital outcomes of the patients treated with abciximab vs eptifibatide (reference category)

\begin{tabular}{lll}
\hline Outcome & Odds ratio & $95 \% \mathbf{~ C l}$ \\
\hline MI & $2.03^{*}$ & $0.37-11.31$ \\
CABG & $5.13^{*}$ & $0.59-44.53$ \\
Contrast nephropathy & $1.5 I^{*}$ & $0.25-9.21$ \\
GI bleed & $1.5 I^{*}$ & $0.24-9.21$ \\
MACE & $3.94 * *$ & $1.39-11.2$ \\
\hline
\end{tabular}

Notes: *Unadjusted; **MACE adjusted for baseline characteristics of PVD, renal failure, and AF.

Abbreviations: $\mathrm{MI}$, myocardial infarction; CABG, coronary artery bypass graft; Gl, gastrointestinal; MACE, major adverse cardiovascular events; PVD, peripheral vascular disease; $A F$, atrial fibrillation.

of the cohorts was attempted. In the eptifibatide group, 14 patients had an ejection fraction of less than $40 \%$ while the abciximab group had 20 patients in this category. However, only $63 \%$ of patients had documented echocardiograms in the study cohort. So, therefore, no attempts were made to analyze comparative echo parameters of left ventricular function to draw any meaningful conclusions.

The higher rate of CABG surgery in the abciximab group is a clinically significant observation. There was higher rate of gastrointestinal bleeding in the abciximab group together with the requirement for postprocedure blood transfusion; once again, a clinically significant observation that did not reach statistical significance. This observation is consistent with the previously published evidence related to higher gastrointestinal bleeding observed with the use of abciximab. ${ }^{7}$

\section{Cost analysis}

The cost associated with standard bolus and infusion administration of abciximab is $\mathrm{A} \$ 1385.19$ per patient episode. The equivalent cost for therapy with eptifibatide is A \$549.11. Thus, the cost differential per patient episode for therapy with abciximab over eptifibatide is $\mathrm{A} \$ \mathbf{8 3 6 . 0 8}$. The average cost per patient bed day in a coronary care unit in Australia is A $\$ 3544.00$. The average stay in coronary care unit for those treated with abciximab is 1.2 days longer than those treated with eptifibatide. This translates into an additional cost of A $\$ 4252.8$ per patient per episode. Thus, the total additional expenditure per patient treated with abciximab over that of eptifibatide is A $\$ 5088.88$ per episode.

\section{Conclusion}

Abciximab and eptifibatide appear to have similar efficacy and safety in the setting of STEMI, treated with primary PCI in the reestablishment of TIMI grade 3 flow in the index artery. However, there is a clinically significant observation of higher in-hospital mortality and major cardiovascular morbidity in the abciximab group. The trend toward higher postprocedural mortality, morbidity, and prolonged hospital stay in the abciximab group is noteworthy. However, these differences did not reach statistical significance in this analysis. Combined analysis showed that the incidence of MACE was higher in the abciximab group. The cost analysis revealed a significantly higher expense associated with the use of abciximab over eptifibatide.

\section{Discussion}

This study evaluated the efficacy and safety of abciximab and eptifibatide in STEMI patients who were treated with primary PCI. This is the first body of evidence to be published in this regard from the Asia-Pacific region and outside of North America. Though retrospective in nature, the findings of this study reveal some very important and relevant information to the clinicians faced with the challenge of making a critical choice between the two intravenous antiplatelet agents. This study and its analyses reflect the current real-life clinical practice at catheterization facilities in the region, where the use and the choice of a GP IIb/IIIa inhibitor is not guideline driven but dependent on operator discretion. It is important to note that both agents were licensed for use in primary PCI and hence contemporaneously used at our institution during the study period. Interestingly and coincidentally, the number of patients in the two groups who fulfilled the inclusion criteria and were treated with either agent during the study period was equal.

Abciximab has been extensively studied in placebocontrolled studies in patients undergoing primary PCI. The CADILLAC ${ }^{8}$ and RAPPORT ${ }^{9}$ trials evaluated the adjunctive use of abciximab during balloon angioplasty for STEMI patients, all of whom received IV heparin. The ISAR-2, ${ }^{10}$ ADMIRAL, ${ }^{11}$ RAPPORT,${ }^{8}$ and ACE ${ }^{12}$ trials evaluated abciximab with coronary stenting in STEMI patients. A 50\%-55\% relative risk reduction in 30-day acute ischemic end points (death, reinfarction, or urgent revascularization) was observed in the abciximab arm of the RAPPORT, ISAR-2, ADMIRAL, and ACE trials. In the CADILLAC trial, however, abciximab did not effect a significant improvement in the 30-day complication rates in patients undergoing stenting, though significant improvement was evident in patients undergoing angioplasty. A meta-analysis by De Luca et $\mathrm{al}^{2}$, including the big five trials previously mentioned, found abciximab therapy to be associated with significant reductions in mortality at 30 days and 6-12 months. This evidence clearly supports the use of abciximab in acute STEMI patients undergoing PCI. 
Although the efficacy of eptifibatide in acute coronary syndrome and post-PCI is well established, ${ }^{3,4}$ there are no placebo-controlled, large randomized-controlled trials in the setting of primary PCI. Although a small, nonrandomized study ${ }^{13}$ concluded that eptifibatide was associated with a higher rate of major adverse cardiac events and subacute thrombosis, no major conclusion can be drawn from this.

Furthermore, no large randomized trial to date has compared abciximab with eptifibatide in STEMI patients undergoing PCI. A respected American registry of contemporary PCI evaluated the safety and efficacy of abciximab and eptifibatide in 3541 STEMI patients undergoing PCI. ${ }^{7}$ Almost $80 \%$ of these patients received eptifibatide, depicting a possible difference in clinical practice between North America and Australia. In concordance with Gurm et $\mathrm{al}^{7}$, we found no statistically significant difference in the incidence of in-hospital death, recurrent MI, strokes, CABG, or need for revascularization between the two arms. However, when comparing the two studies closely, our data showed a trend toward higher rates in the abciximab group for CABG $(5.6 \% \mathrm{vs}$ $2.3 \%)$, revascularization $(6.5 \%$ vs $1.6 \%)$, stroke $(2.4 \%$ vs $0.7 \%)$, and consequently MACE ( $20.8 \%$ vs $8.4 \%)$.

Though statistically insignificant, the differences in the baseline clinical parameters between the two treatment arms in our study warrant further examination. A plausible explanation for this is that interventionists trust abciximab more with high-risk patients as it has the highest volume of published evidence in primary PCI. This theory is supported by the fact that the abciximab group had higher rates of prior MI, PVD, and renal disease. Procedurally, they also had higher rates of cardiac arrest, cardiogenic shock, and use of IABP. The higher use of preprocedural UFH and lower rates of clopidogrel use may be a sign of caution by the interventionist to reduced possible bleeding risks if an urgent $\mathrm{CABG}$ is warranted. Cardioprotective drugs, such as statins, beta-blockers, and ACE inhibitors, were the standard of care during the study period. The difference in the use of these drugs between the groups cannot be explained. It is, however, evident that the abciximab group may have been at a higher risk as they were not on optimal medical management prior to the STEMI event.

A purely evidence-based medicine approach to the use of GP IIb/IIIa inhibitors in STEMI patients post-PCI would conclude that abciximab is the only agent that should be used in that setting. A randomized trial comparing a newer agent to abciximab is unlikely to go ahead due to the required size of the trial, and consequent cost, which would be needed to prove noninferiority of the newer agent. Despite this, small molecule GP IIb/IIIa inhibitors are routinely used in clinical practice, primarily due to their price advantage over abciximab and their perceived noninferiority. More evidence in this regard is useful for the clinicians to assist in their decision-making process. The results of this observational study add weight to the argument that eptifibatide has similar safety and efficacy to abciximab over the short term when adjunctively used in the setting of primary PCI. This study carries inherent limitations due to its design. It does, however, represent current real-life clinical practice relevant to the Asia-Pacific region. Although attempts were made in statistical analysis to adjust the data for any differences, we cannot exclude the possibility that unaccounted factors influenced the outcome. Finally, this study focused on short-term outcomes, and consequently, no long-term safety and efficacy conclusions can be made from this data. Ideally, however, a randomized prospective study should be undertaken, comparing the safety and efficacy of both drugs in the short and long term.

\section{Disclosure}

The authors report no conflicts of interest in this work.

\section{References}

1. Kandzari DE, Hasselblad V, Tcheng JE, et al. Improved clinical outcomes with abciximab therapy in acute myocardial infarction: a systematic overview of randomized clinical trials. Am Heart J. 2004;147(3): $457-462$

2. De Luca G, Suryapranata H, Stone GW, et al. Abciximab as adjunctive therapy to reperfusion in acute ST-segment elevation myocardial infarction: a meta-analysis of randomized trials. JAMA. 2005;293: 1759-1765.

3. ESPRIT Investigators. Enhanced Suppression of the Platelet IIb/IIIa Receptor with Integrilin Therapy. Novel dosing regimen of eptifibatide in planned coronary stent implantation (ESPRIT): a randomised, placebo-controlled trial Lancet. 2000;356(9247):2037-2044. [Published correction appears in Lancet. 2001;357(9265):1370].

4. PURSUIT Trial Investigators. Platelet Glycoprotein IIb/IIIa in Unstable Angina: Receptor Suppression Using Integrilin Therapy. Inhibition of platelet glycoprotein IIb/IIIa with eptifibatide in patients with acute coronary syndromes. N Engl J Med. 1998;339(7):436-443.

5. Raveendran G, Ting HH, Best PJ, et al. Eptifibatide vs abciximab as adjunctive therapy during primary percutaneous coronary intervention for acute myocardial infarction. Mayo Clin Proc. 2007;82(2): 196-202.

6. Zeymer U, Wienbergen H. A review of clinical trials with eptifibatide in cardiology. Cardiovasc Drug Rev. 2007;25(4):301-315.

7. Gurm HS, Smith DE, Collins JS, et al; Blue Cross Blue Shield of Michigan Cardiovascular Consortium (BMC2). The relative safety and efficacy of abciximab and eptifibatide in patients undergoing primary percutaneous coronary intervention: insights from a large regional registry of contemporary percutaneous coronary intervention. J Am Coll Cardiol. 2008;51(5):529-535.

8. Stone GW, Grines CL, Cox DA, et al; Controlled Abciximab and Device Investigation to Lower Late Angioplasty Complications (CADILLAC) Investigators. Comparison of angioplasty with stenting, with or without abciximab, in acute myocardial infarction. N Engl J Med. 2002;346(13): 957-966. 
9. Brener SJ, Barr LA, Burchenal JE, et al; ReoPro and Primary PTCA Organization and Randomized Trial (RAPPORT) Investigators. Randomized, placebo-controlled trial of platelet glycoprotein IIb/IIIa blockade with primary angioplasty for acute myocardial infarction. Circulation. 1998;98(8):734-741.

10. Neumann FJ, Kastrati A, Schmitt C, et al. Effect of glycoprotein $\mathrm{IIb} / \mathrm{III}$ a receptor blockade with abciximab on clinical and angiographic restenosis rate after the placement of coronary stents following acute myocardial infarction. J Am Coll Cardiol. 2000;35(4):915-921.

11. Montalescot G, Barragan P, Wittenberg O, et al; ADMIRAL Investigators. Abciximab before Direct Angioplasty and Stenting in Myocardial Infarction Regarding Acute and Long-Term Follow-up. Platelet glycoprotein IIb/IIIa inhibition with coronary stenting for acute myocardial infarction. N Engl J Med. 2001;344(25):1895-1903.
12. Antoniucci D, Rodriguez A, Hempel A, et al. A randomized trial comparing primary infarct artery stenting with or without abciximab in acute myocardial infarction. J Am Coll Cardiol. 2003;42(11): 1879-1885.

13. Kaul U, Gupta RK, Haridas KK, et al; Integrilin in Acute Myocardial Infarction (INAMI) Stenting Study Investigators. Platelet glycoprotein IIb/IIIa inhibition using eptifibatide with primary coronary stenting for acute myocardial infarction: a 30-day follow-up study [published correction appears in Catheter Cardiovasc Interv. 2003;59(3):419] Catheter Cardiovasc Interv. 2002;57(4):497-503.

\section{Publish your work in this journal}

Research Reports in Clinical Cardiology is an international, peerreviewed, open access journal publishing original research, reports, editorials, reviews and commentaries on all areas of cardiology in the clinic and laboratory. The manuscript management system is completely online and includes a very quick and fair peer-review system.
Visit http://www.dovepress.com/testimonials.php to read real quotes from published authors. 